\title{
Acquired Skin Fragility Syndrome in a Juvenile Cat Following a Routine Ovariohysterectomy
}

\author{
Ebru Karakaya Bilen' ${ }^{1}$ \& Mustafa Barış Akgül²
}

\begin{abstract}
Background: Acquired skin fragility syndrome (ASFS) is a rare condition, which is characterized by spontaneous fragility of the skin and an absence of hyperextensibility. Even though the real pathogenesis of ASFS remains unknown that is reported generally with some iatrogenic causes and severe diseases. Thus, based on the clinical findings this is the first report of describes the case and treatment of feline acquired skin fragility syndrome following a routine ovariohysterectomy. Case: An 8-month-old domestic shorthair female cat was brought to the Siirt University Animal Health Application and Research Center for ovariohysterectomy operation. Before the operation physical examination of the animal revealed body temperature, heart rate, respiratory rate, the color of mucosas, and lymph nodes were determined normally. Besides, there is no hematological and biochemical problem detected. The cat had no previous history of several infections or systemic disease. A routine ovariohysterectomy procedure was applied under general anesthesia and the cat was discharged on the same day. Three days after that a spontaneously developed cutaneous laceration below the left scapular region was determined by the cat owner. During the clinical examination, it was determined that the cat was sensitive to touch against the left scapular area. Multiple spontaneous skin tear was revealed over the left scapular region while shaving for better inspection but did not obtain any problem with incision line. To identify the underlying cause of skin tearing, hematological and biochemical tests were done but the animal's results were found within the normal references. Also, rapid blood tests were performed for feline leukemia virus and immunodeficiency virus, and none of them were positive. Additionally, the skin was not hyperextensible. Although the clinicopathological abnormalities were observed on the skin, there were no abnormalities in the vital signs of the cat. Based on the clinical status of the cat, daily regular wound cleaning and a wet-to-dry bandage were applied for two weeks. Skin therapy based on the use of dexpanthenol, vitamin E, and vitamin $\mathrm{C}$ with zinc was preferred to improve skin health. All lesions on the skin of the cat completely recovered and a follow-up visit for several weeks was recommended to the cat owner.

Discussion: There have been reports that acquired skin fragility syndrome may be related to hepatic diseases, some feline viral infections, hyperadrenocorticism, or use of a long time progestational drugs. Also, acquired skin fragility syndrome can be seen in a congenital disorder known as cutaneous asthenia which is described generally in young cats. Cutaneous asthenia and acquired skin fragility syndrome are difficult to distinguish from each other even though histological examination was made. Although the cat in this report is young, there was no history of skin problems and skin hyperextensible until presentation. No specific treatment protocol described for this skin problem has been reported. Moreover, vitamins and minerals may be used for wound treatment and strengthening the skin. Ovariohysterectomy is the most common surgical technique used for sterilization of cats however; it can cause some complications, such as acute stress. Unfortunately, the exact etiology is not detected in this case report but it is thought to be that stress of ovariohysterectomy might be triggered to spontaneous skin tearing.
\end{abstract}

Keywords: Fragile syndrome, skin, ovariohysterectomy, cat.

DOI: $10.22456 / 1679-9216.105305$

${ }^{1}$ Department of Obstetrics and Gynecology \& ${ }^{2}$ Department of Surgery, Faculty of Veterinary Medicine, Siirt University, Siirt, Turkey. CORRESPONDENCE: E. Karakaya Bilen [ebilen@ siirt.edu.tr]. Department of Obstetrics and Gynecology, Faculty of Veterinary Medicine, Siirt University. 56100 Siirt, Turkey. 


\section{INTRODUCTION}

Acquired skin fragility syndrome (ASFS) is an uncommon clinical condition generally seen in middle-aged to older cats with no previous history of skin disorder $[1,10,11]$. Even though the pathogenesis of this syndrome is unknown it is most commonly reported with conditions such as cholangiocarcinoma, cholangiohepatitis, hepatic lipidosis, disseminated histoplasmosis, pancreatic and hepatic carcinoma, feline infectious peritonitis, multicentric follicular lymphoma, diabetes mellitus, or extensive use of progestational compounds $[2,3,7,8,12,15]$. Regardless of the etiology, ASFS is clinically determined by extremely fragile and thin skin, severe tearing and shedding of skin from minor trauma or handling, and with or without evidence of hyperextensibility [5].

The purpose of the present case is to describe the clinical presentation and treatment of acquired skin fragility syndrome following a routine ovariohysterectomy in a juvenile cat without any clinical diseases.

\section{CASE}

An 8-month-old female mixed-breed household cat, weighing $3 \mathrm{~kg}$, was presented to the Department of Obstetrics and Gynecology, Faculty of Veterinary Medicine, Siirt University, for routine ovariohysterectomy operation. On clinical examination such as body temperature, respiratory rate, heart rate, capillary refill time, and mucous membrane color were all within normal reference ranges. After completion of the physical examination, routine hematology was performed. The cat was healthy and not receiving any medication before the ovariohysterectomy. When she was a kitten the cat was found on the street after that she was fed commercially prepared dry cat food and lived exclusively at home. Vaccinations and parasite therapy were up-to-date. For flank ovariohysterectomy, the patient was pre-medicated with $2 \mathrm{mg} / \mathrm{kg}$ of $2 \%$ xylazine $\left(\text { Xylazinbio }^{\odot}\right)^{1}$; anesthesia was induced using $8 \mathrm{mg} / \mathrm{kg}$ of $10 \%$ ketamine $\mathrm{HCl}\left(\mathrm{Ketasol}^{\circledR}\right)^{2}$. Preoperatively, shave off the hair, disinfection and antiseptic applications of the operation site were performed for aseptic surgery. Ovariohysterectomy was performed according to generally accepted surgical guidelines. Postoperative analgesia was provided via a single dose of $0.3 \mathrm{mg} / \mathrm{kg}$ of meloxicam $\left(\text { Demelox }^{\odot}\right)^{3}$, and a dose of $25 \mathrm{mg} / \mathrm{kg}$ of clavulanate-potentiated amoxicillin $\left(\text { Synulox }{ }^{\odot}\right)^{4}$ was given to provide antimicrobial prophylaxis. Three days later following the flank ovariohysterectomy the cat owners reported that their animal had reduced activity, hypersensitivity for touching, and developed local skin bleeding and swelling on the left area. On the other hand, she was normal and eating well. During the detailed clinical examination was performed multiple swelling areas appeared over the left flank. This appeared painful on palpation. When regional haircut applied for an exhaustive examination of the skin, spontaneous multiple skin lacerations were occurred (Figure 1).

The cat had multiple, painful skin tears with irregular edges on the left flank. These lesions were revealing the underlying muscle and there was only a slight amount of bleeding. Hyperextensibility of the skin were not detected on physical examination. A local reaction to a non-steroidal anti-inflammatory injection administered subcutaneously was thought but the injection area was not at this site. Physical examination and routine hematology were performed (Table 1), rectal temperature was $37.8^{\circ} \mathrm{C}$, heart rate was 120 pulses $/ \mathrm{min}$ and respiration rate was 16 breaths/min. No abnormalities in mucous membrane color were noted.

Diagnostic procedures also included blood serum biochemistry panel to eliminate some diseases associated with these dermal lesions (Table 2). The rapid blood tests for feline leukemia virus (FeLV) and feline immunodeficiency virüs (FIV) were negative (FIV Ab/FeLV Ag Test Kit Anigen $\left.{ }^{\circledR}\right)^{5}$. Because of sufficient appetite and water consumption, serum infusion therapy was not implemented. Staged wound closure was performed with a combination of daily wound cleaning ethacridine lactate (Rivanolum powder $\left.{ }^{\circledR}\right)^{6}$ solution and debridement, and a wet-to-dry bandage which is non-adherent dressings initially with a centella asiatica

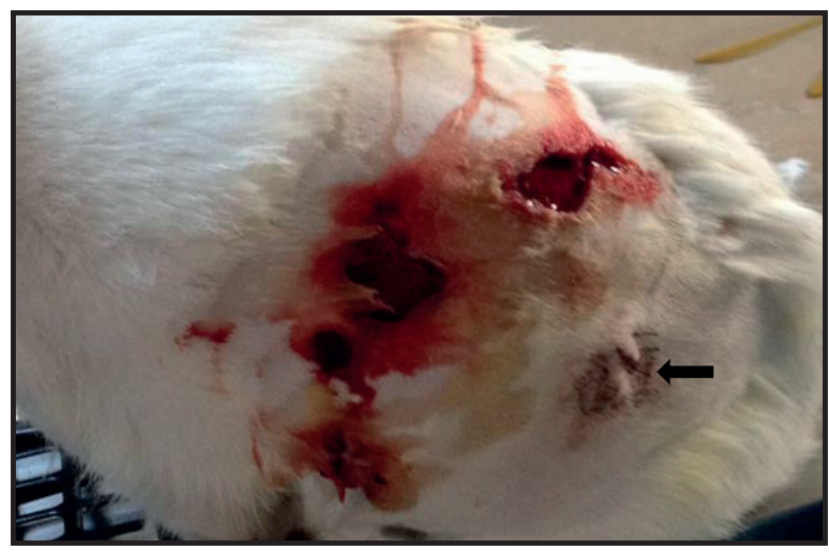

Figure 1. Clinical appearance of the case. The arrow points out the ovariohysterectomy wound on the flank region. 
Table 1. Haematological findings for the cat with skin fragility syndrome.

\begin{tabular}{ccc}
\hline Parameter & Value for this case & Reference interval \\
\hline White blood cells & $7 \times 10^{9} / \mathrm{L}$ & $5.5-19.0 \times 10^{9} / \mathrm{L}$ \\
Neutrophils & $10.8 \times 10^{9} / \mathrm{L}$ & $2.1-15.0 \times 10^{9} / \mathrm{L}$ \\
Lymphocytes & $3.9 \times 10^{9} / \mathrm{L}$ & $0.8-7.0 \times 10^{9} / \mathrm{L}$ \\
Monocytes & $0.3 \times 10^{9} / \mathrm{L}$ & $0.0-1.9 \times 10^{9} / \mathrm{L}$ \\
Red blood cells & $9.26 \times 10^{12} / \mathrm{L}$ & $4.60-10.00 \times 10^{12} / \mathrm{L}$ \\
Eosinophils & $1.5 \%$ & - \\
Haemoglobin & $13.0 \mathrm{~g} / \mathrm{dL}$ & $9.3-15.3 \mathrm{~g} / \mathrm{dL}$ \\
Haematocrit & $42.6 \%$ & $28.0-49.0 \%$ \\
Mean corpuscular volume & $46.1 \mathrm{fL}$ & $39.0-52.0 \mathrm{~L}$ \\
Mean corpuscular haemoglobin & $13.8 \mathrm{pg}$ & $13.0-21.0 \mathrm{pg}$ \\
Mean corpuscular haemoglobin concentration & $30.5 \mathrm{~g} / \mathrm{dL}$ & $30.0-38.0 \mathrm{~g} / \mathrm{dL}$ \\
Platelets & $169 \times 10^{9} / \mathrm{L}$ & $100-514 \times 10^{9} / \mathrm{L}$ \\
\hline
\end{tabular}

Table 2. Serum biochemistry results for the cat with skin fragility syndrome.

\begin{tabular}{ccc}
\hline Analyte & Value for this case & Reference interval \\
\hline Glucose & $85 \mathrm{mg} / \mathrm{dL}$ & $60-120 \mathrm{mg} / \mathrm{dL}$ \\
ALP & $76 \mathrm{IU} / \mathrm{L}$ & $20-90 \mathrm{IU} / \mathrm{L}$ \\
ALT & $48 \mathrm{IU} / \mathrm{L}$ & $6-83 \mathrm{IU} / \mathrm{L}$ \\
Total protein & $70 \mathrm{~g} / \mathrm{L}$ & $54-78 \mathrm{~g} / \mathrm{L}$ \\
Albumin & $21 \mathrm{~g} / \mathrm{L}$ & $21-33 \mathrm{~g} / \mathrm{L}$ \\
Blood urea nitrogen & $0.35 \mathrm{~g} / \mathrm{L}$ & $0.10-0.40 \mathrm{~g} / \mathrm{L}$ \\
Creatinine & $15 \mathrm{mg} / \mathrm{L}$ & $10-20 \mathrm{mg} / \mathrm{L}$ \\
Total bilirubin & $2.6 \mathrm{mg} / \mathrm{L}$ & $1.5-5.0 \mathrm{mg} / \mathrm{L}$ \\
Sodium & $148 \mathrm{mmol} / \mathrm{L}$ & $145-155 \mathrm{mmol} / \mathrm{L}$ \\
Potassium & $4.3 \mathrm{mmol} / \mathrm{L}$ & $3.5-5.5 \mathrm{mmol} / \mathrm{L}$ \\
Ionised calcium & $1.20 \mathrm{mmol} / \mathrm{L}$ & $1.10-1.40 \mathrm{mmol} / \mathrm{L}$ \\
\hline
\end{tabular}

$\left(\text { Madecassol }^{\circledR}\right)^{7}$, dexpanthenol (Bepanthene ${ }^{\circledR}$ plus cream $)^{7}$ and zinc oxide cream (Dermolife $\left.{ }^{\circledR}\right)^{8}$. Fortunately, any additional lesions weren't developed. Complete closure and resolution of all cutaneous lesions were achieved in 5 weeks. Antimicrobial prophylaxis based on the use of $25 \mathrm{mg} / \mathrm{kg}$, SID, of amoxicillin trihydrate $\left(\text { Largopen }{ }^{\circledR}\right)^{9}$ was also included in the treatment. The skin therapy of the patient was supported with $0.5 \mathrm{~mL}$, 2 times every other week of dexpanthenol (Bepanthene $\left.^{\circledR}\right)^{10}, 100$ IU, SID, of vitamin E (Evicap $\left.{ }^{\circledR}\right)^{11}$, and $5 \mathrm{~mL}$, SID, of vitamin $\mathrm{C}$ with zinc, $\left(\text { Zinco- } \mathrm{C}^{\circledR}\right)^{12}$ for healthy skin during 2 weeks. The following days the cat's condition status was good, the cat did not have any other cutaneous lesions and the ovariohysterectomy wound was healed uneventfully (Figure 2).

\section{DISCUSSION}

Acquired skin fragility syndrome, is generally reported concomitantly with used excessive steroidal hormones, severe inflammatory, infectious or neoplastic conditions, however, the pathogenesis remains usually unknown. Clinically, cats with ASFS are readily noticed because of the dermatological disorder which is extreme cutaneous fragility in the absence of 


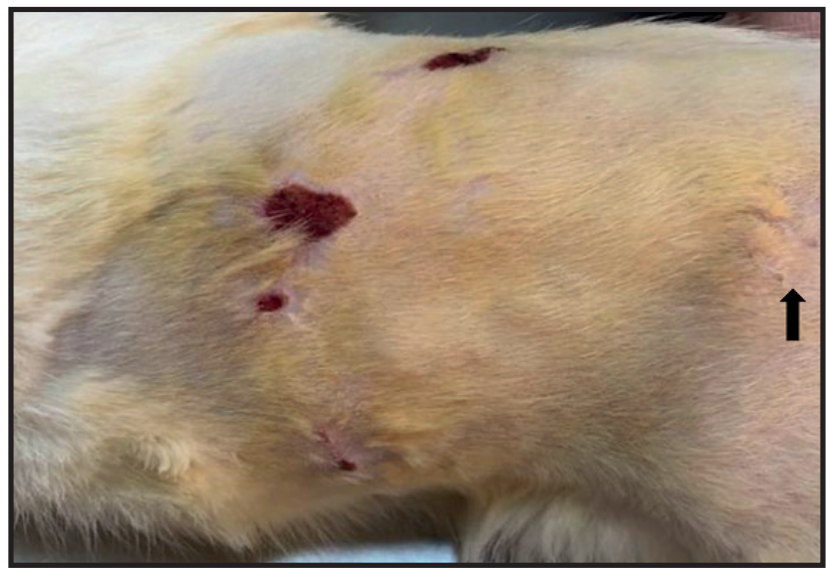

Figure 2. Clinical recovery of the case. The arrow points out the ovariohysterectomy area on the flank region.

hyperextensibility of the skin $[7,11]$. So far, only one report represents a juvenile cat with severe ASFS and multiple large cutaneous lacerations [8].

In cats, ASFS is characterized histologically by epidermal thinning, atrophying epidermis (one nucleated layer) with mild orthokeratotic hyperkeratosis, disorganizing dermal collagen fibers, and shown telogen phase in most hair follicles $[2,8,15]$. Some of these characteristics also pertain to cutaneous asthenia (Ehlers-Danlos syndrome) which is a congenital disorder of collagen production in cats characterized by cutaneous hyperextensibility, fragility, and poor wound healing [9]. Besides that, the cutaneous fragility affected cat could show articular laxity and ocular abnormalities. Masson's trichrome staining can be used in an attempt to distinguish cutaneous asthenia and ASFS, however, staining abnormalities of collagen fibers are seen in both problems [4]. On the other hand, staining abnormality was found tended to be milder in cats with ASFS [4]. Even though histologically, some cases of cutaneous asthenia are difficult to distinguish from ASFS, clinically differentiation of ASFS depends on the patient's history and the absence of hyperextensibility $[1,10]$. The skin extensibility index is a very helpful clinical diagnostic tool for supporting to distinguish from cutaneous asthenia to ASFS $[1,6]$. The skin extensibility examination according to Hansen et al. [6] was performed in this case and the extensibility of skin was not observed. Unfortunately, histopathological findings could not be included; however, these clinical findings and history of the patient were consistent with the acquired feline fragile syndrome. Moreover, a genetic study identified a heterozygous single-nucleotide deletion in COL5A1 in a cat with cutaneous asthenia
[14]. Genetic analysis as a diagnostic tool could not be performed because of the cat owner not donating.

Acquired skin fragility syndrome is a poorly understood disorder with multiple different etiology, some cases have not been related to a known disease process [11]. There are some reports association between ASFS and lymphoma [2], cholangiocarcinoma [10], hepatic lipidosis with feline infectious peritonitis [15], cholangiohepatitis and hepatic lipidosis [3], or iatrogenic hyperadrenocorticism [8]. In the present case, iatrogenic cause such as excessive use of glucocorticoids or any progestational compound was eliminated based on anamnesis. Also, clinical history and the results of laboratory examinations were not matching with hyperadrenocorticism, diabetes mellitus, or liver diseases. The exact pathogenesis regarding the dermatological abnormalities seen in this case remains unknown but it might be related to the effect of surgical stress. As we are known, cats are easily stressed animals. Cortisol concentration increased in response to ovariohysterectomy which is a stressful experience for the cat and dog [13]. A stress response which including inflammatory changes and an increased tendency to coagulation after the operation were developed in cats and dogs that are sterilized or castrated. For now, it is not possible to explain definitively a causal relationship between any stress responses and ASFS.

In the present case, acquired skin fragility syndrome noted three days after the routine ovariohysterectomy but to determine the underlying reason was failed. We cannot decline the probability of this association being incidental in this case but it may be necessary to include routine ovariohysterectomy on the list of cases associated with acquired skin fragility syndrome in cats.

\section{MANUFACTURERS}

${ }^{1}$ Bioveta. Ankara, Turkey.

${ }^{2}$ In terhas Veteriner Ilaçlari. Ankara, Turkey.

${ }^{3}$ Denova Ilac Sanayi ve Ticaret Llc. Adana, Turkey.

${ }^{4}$ Pfizer. Istanbul, Turkey.

${ }^{5}$ BioNote Inc. Hwaseong-si. Gyeonggi-do, China.

${ }^{6}$ Istanbul Ilaç. Istanbul, Turkey.

${ }^{7}$ Bayer Türk Kimya Sanayi Llc. Istanbul, Turkey.

${ }^{8}$ Denizpharma Ilac Sanayi ve Ticaret Llc. Istanbul, Turkey.

${ }^{9}$ Bilim Ilaç. Istanbul, Turkey.

${ }^{10}$ Roche. Istanbul, Turkey.

${ }^{11}$ Koçak Farma. Istanbul, Turkey.

${ }^{12}$ Berko Ilaç. Istanbul, Turkey.

Declaration of interest. The authors report no conflicts of interest. The authors alone are responsible for the content and writing of paper. 


\section{REFERENCES}

1 Butler W.F. 1975. Fragility of the skin in a cat. Research in Veterinary Science. 19(2): 213-216.

2 Crosaz O., Vilaplana-Grosso F., Alleaume C., Cordonnier N., Bedu-Leperlier A.S., Marignac G., Hubert B. \& Rosenberg D. 2013. Skin fragility in a cat with multicentric follicular lymphoma. Journal of Feline Medicine and Surgery. 15(10): 953-958.

3 Daniel A.G., Lucas S.R., Reche Júnior A., Monteiro P.R.G., Ramos D., Pires C.G. \& Sinhorini I.L. 2010. Skin fragility syndrome in a cat with cholangiohepatitis and hepatic lipidosis. Journal of Feline Medicine and Surgery. 12(2): 151-155.

4 Fernandez C.J., Scott D.W., Erb H.N. \& Minor R.R. 1998. Staining abnormalities of dermal collagen in cats with cutaneous asthenia or acquired skin fragility as demonstrated with Masson's trichome stain. Veterinary Dermatology. 9(1): 49-54.

5 Gross T.L., Ihrke P.J. \& Walder E.J. 2005. Veterinary Dermatopathology: A Macroscopic and Microscopic Evaluation of Canine and Feline Skin Disease. 2nd edn. Oxford: Blackwell Science, pp.389-392.

6 Hansen N., Foster S.F., Burrows A.F., Mackie J. \& Malik R. 2015. Cutaneous asthenia (Ehlers-Danlos-like syndrome) of Burmese cats. Journal of Feline Medicine and Surgery. 17(11): 954-963.

7 Hoenig M. 2002. Feline hyperadrenocorticism - where are we now? Journal of Feline Medicine and Surgery. 4(4): 171-174.

8 McKnight C.N., Lew L.J. \& Gamble D.A. 2018. Management and closure of multiple large cutaneous lesions in a juvenile cat with severe acquired skin fragility syndrome secondary to iatrogenic hyperadrenocorticism. Journal of the American Veterinary Medical Association. 252(2): 210-214.

9 Patterson D.F. \& Minor R.R. 1977. Hereditary fragility and hyperextensibility of the skin of cats. A defect in collagen fibrillogenesis. Laboratory Investigation. 37(2): 170-179.

10 Regnier A. \& Pieraggi M.T. 1989. Abnormal skin fragility in a cat with cholangiocarcinoma. Journal of Small Animal Practice. 30(7): 419-23.

11 Scott D.W., Miller W.H. \& Griffin C.E. 2001. Miscellaneous skin diseases: feline acquired skin fragility. In: Muller and Kirk's Small Animal Dermatology. 6th edn. Philadelphia: Saunders, pp.1170-1173.

12 Sequeira J.L., Rocha N.S., Bandarra E.P., Figueiredo M.A. \& Eugenio F.R. 1999. Collagen dysplasia (cutaneous asthenia) in a cat. Veterinary Pathology. 36(6): 603-606.

13 Smith J.D., Allen S.W., Quandt J.E. \& Tackett R.L. 1996. Indicators of postoperative pain in cats and correlation with clinical criteria. American Journal of Veterinary Research. 57(11): 1674-1678.

14 Spycher M., Bauer A., Jagannathan V., Frizzi M., De Lucia M. \& Leeb T. 2018. A frameshift variant in the COL5A1 gene in a cat with Ehlers-Danlos Syndrome. Animal Genetics. 49(6): 641-644.

15 Trotman T.K., Mauldin E., Hoffmann V., Piero F.D. \& Hess R.S. 2007. Skin fragility syndrome in a cat with feline infectious peritonitis and hepatic lipidosis. Veterinary Dermatology. 18(5): 365-369. 